J. Lake Sci. (湖泊科学), 2014, 26(4):616-624

http: //www. jlakes.org. E-mail : jlakes@niglas.ac.cn

(C) 2014 by Journal of Lake Sciences

\title{
新疆艾比湖干涸湖底不同景观单元蒸发盐分布与变化特征”
}

\author{
葛拥晓 ${ }^{1,2}$,吉力力・阿不都外力 ${ }^{1 * *}$, 马 龙 ${ }^{1}$, 张登清 ${ }^{1,2}$ \\ (1: 中国科学院新疆生态与地理研究所, 荒漠与绿洲生态国家重点实验室, 乌鲁木齐 830011) \\ (2: 中国科学院大学,北京 100049)
}

\begin{abstract}
摘 要: 盐尘暴是由干旱、半干旱区尾问湖干涸湖底及其附近盐质荒漠风蚀所导致的一种灾害性极强的天气现象. 盐尘 主要来自风蚀过程中干涸湖底盐分的释放. 由于干涸湖底不同的植被覆盖状况, 导致风蚀过程中盐分损失不同. 为了解 风蚀过程中不同景观单元下盐分分布与变化特征, 选择艾比湖干涸湖底自然状态下典型的 6 种景观单元 (胡杨林带 (Landscape 1, 简写为 L1)、乔本结合带 ( L2)、草本结合带 (L3)、芦苇荒漠带 (L4)、梭梭荒漠带 (L5)、无植被覆盖 ( L6) ) , 于 2011 年 6 月初和 10 月初 2 次采集沉积物样品, 运用方差分析方法, 研究各个景观单元下盐分的分布与季节变化特征. 结果表明:1) 2 次采样不同景观单元 $0 \sim 30 \mathrm{~cm}$ 和 $30 \sim 60 \mathrm{~cm}$ 处阳离子 $\mathrm{Na}^{+} 、 \mathrm{~K}^{+} 、 \mathrm{Mg}^{2+}$ 含量均存在显著差异, 其中 $\mathrm{Na}^{+}$含 量存在极显著差异且含量最高, 而不同景观单元 $0 \sim 30 \mathrm{~cm}$ 和 $30 \sim 60 \mathrm{~cm}$ 处阴离子 $\mathrm{Cl}^{-} 、 \mathrm{SO}_{4}^{2-}$ 含量均存在显著差异, $\mathrm{CO}_{3}^{2-} 、 \mathrm{HCO}_{3}^{-}$含量甚微;2) 干涸湖底沉积物的主要盐分类型是 $\mathrm{NaCl}$, 其次是 $\mathrm{CaSO}_{4}$, 其它盐分含量较小, 且不同景观单元 相同深度沉积物盐分含量存在显著差异. 无论是盐分离子组成还是含量, L5 均最高, 其次是 L6, 而 L2 均最低. 随着深度 的增加, 不同景观单元沉积物中的盐分含量均呈现降低的趋势. 随着时间变化, 景观单元 L2、L3、L4、L5、L6 盐分含量有不 同程度的增加, 而 L1 盐分含量减少; 3) 在小尺度范围内, 局地气候条件相对均一, 地下水矿化度、地下水埋深及沉积物性 质差别不大,不同景观类型是影响盐分表聚的主要因素.
\end{abstract}

关键词: 干涸湖底; 蒸发盐; 景观单元;艾比湖

\section{Variation and distribution of evaporated salt under different landscape units in the playa of Lake Ebinur, Xinjiang Province}

\author{
GE Yongxiao ${ }^{1,2}$, ABUDUWAILI Jilili ${ }^{1}$, MA Long $^{1}$ \& ZHANG Dengqing ${ }^{1,2}$ \\ (1: State Key Laboratory of Desert and Oasis Ecology, Xinjiang Institute of Ecology and Geography, Chinese Academy of Sci- \\ ences, Urumqi 830011 , P. R. China) \\ (2: University of Chinese Academy of Sciences, Beijing 100049, P. R. China)
}

\begin{abstract}
Salt dust storm which mainly released from the dry lakebed is an extremely disastrous weather phenomenon caused by wind erosion of playa in arid and semi-arid land. Due to different kinds of vegetation covered in the dry lakebed, the salt loss amount is different during wind erosion process. In order to understand the distribution and variation of the salt content under different landscape units, six typical landscape units under natural state were selected as research objects in the dry lakebed of Lake Ebinur. In early June and early October 2011, sediment samples were collected twice. Mathematical statistical methods were used to study the distribution and seasonal variation of salt composition and content. The results showed that the $\mathrm{Na}^{+}$contents in sediments of the same two depths from $0 \mathrm{~cm}$ to $60 \mathrm{~cm}$ were significantly different among the six different landscape types ( L1 to L6, characterized with decreasing vegetation coverage) in early June and early October, so do $\mathrm{K}^{+}$and $\mathrm{Mg}^{2+}$. In addition, $\mathrm{Na}^{+}$had a highly significant difference with the highest content. The contents of $\mathrm{Cl}^{-}, \mathrm{SO}_{4}^{2-}$ from $0 \mathrm{~cm}$ to $30 \mathrm{~cm}$ were significantly different among different landscape units, this result is the same as samples from $30 \mathrm{~cm}$ to $60 \mathrm{~cm}$, although the $\mathrm{CO}_{3}^{2-}$ and $\mathrm{HCO}_{3}^{-}$contents were low. The main type of salt in sediments was $\mathrm{NaCl}$, followed by $\mathrm{CaSO}_{4}$, and other types of salt were in very low concentrations. There was a significant difference among the salt contents of sediments from the same depth under different landscape units.
\end{abstract}

* 国家自然科学基金项目 $(41101190,41071139)$ 和中国科学院知识创新工程重要方向性项目 (KZCX2-EW-308) 联合资 助. 2013-06-05 收稿;2013-12-09 收修改稿. 葛拥晓(1987 ), 男,博士研究生;E-mail:yongxiao-ge@ hotmail. com.

** 通信作者;E-mail: jilil@ ms. xjb. ac. cn. 
In term of the ionic composition and salt content, the content of L5 was the highest, followed by L6, and L2 was the lowest. With increasing depth, the salt contents of sediments from different landscape units showed a decreasing trend. Over time, the salt contents of landscape units L2, L3, L4, L5, L6 increased in varying degrees, only L1 turned out reduce. It is suggested that different landscape units was the main factor affecting the salt accumulation in the range of small-scale of which the local climate conditions, groundwater salinity, groundwater depth and sediment properties are relatively homogeneous.

Keywords: Dry lakebed (playa); evaporated salt; landscape unit; Lake Ebinur

干涸湖底是干旱区尾问湖地区重要的景观类型之一, 通常指世界干旱半干旱地区内陆盆地中的尾问盐 湖或集水洼地水面退缩后裸露出来的部分及其积盐较严重的滨岸地带 ${ }^{[1-2]}$, 其物质组成主要是湖相松散富 盐沉积物. 世界范围内, 干涸湖底多分布在中西亚、美国西部、北非、澳大利亚及中国西北等地的干旱半干旱 地区 ${ }^{[3-4]}$.

艾比湖作为一个典型的内陆干旱区封闭型湖泊, 对气候和环境变化的响应非常敏感. 晚更新世晚期开 始, 由于流域气候逐渐变干, 艾比湖不断萎缩 ${ }^{[5-6]} .20$ 世纪下半叶以来, 在区域气候波动和人类活动的双重影 响下, 艾比湖湖面持续缩减, 若不调人水量, 则将在 2050 年完全干涸 ${ }^{[7]}$. 目前, 艾比湖已经形成了大面积历 史时期干涸湖底 (1950s 的湖岸线以外, 晚更新世的湖岸线以内) 和现代间歇性干涸湖底 (1950s 的湖岸线以 内), 干涸湖底的地下水位很浅, 且地下水矿化度很高, 高矿化度地下水蒸发携带的盐分在毛管效应下表聚, 形成干旱区特有的盐漠景观 ${ }^{[8-9]}$, 成为危害新疆北部最主要的尘源之一 ${ }^{[10]}$. 每逢春、冬季大风期, 裸露湖底的 松散沉积物在阿拉山口强风驱动下强烈风蚀. 每年被大风吹走的盐尘高达 $4.8 \times 10^{6} \mathrm{t}$, 成为下风向广大地区 盐尘灾害的源头, 盐尘中富含密度很高、粒径很细的 $\mathrm{NaCl}$ 等物质, 可以作为气溶胶长期悬浮于大气中, 影响 土壤盐渍化,加速冰雪消融, 对天山北坡绿洲生态安全造成严重威胁 ${ }^{[1-12]}$.

不同景观类型下植被生理生态、地下水埋深、蒸发量等不同造成盐分含量并不相同. 在风蚀严重的艾比 湖干涸湖底, 由于不同的景观类型对风速的阻截作用不同, 致使风蚀程度不同, 从而进一步导致沉积物盐分 含量特征对风蚀具有不同的响应. 因此, 沉积物盐分含量及其变化特征可以反映不同景观类型的抗风蚀能 力, 对不同景观类型下沉积物盐分含量分布与变化特征进行研究, 可以明确盐尘暴发生过程中不同景观类 型盐尘释放的相对强度, 即对盐尘暴的相对贡献量. 因此, 本文选择艾比湖东南部的历史时期干涸湖底为研 究区, 选取艾比湖比较典型的 6 种景观单元, 以不同景观单元下的沉积物为研究对象, 重点研究: (1) 艾比 湖干涸湖底不同景观单元下沉积物的可溶性盐分组成特征及其差异. (2) 不同景观单元下盐分含量的分布 以及随时间的变化特征, 旨在了解干涸湖底风蚀过程中沉积物盐分分布与含量分异特征; 不同景观单元下 沉积物风蚀过程中盐分变化特征, 增加干涸湖底不同景观类型风蚀过程中盐尘释放差异的初步认识, 同时 为不同景观类型的风蚀控制采取有效的生物和工程措施提供科学参考, 为防治盐尘暴灾害提供基础数据和 科学依据.

\section{1 研究方法}

\section{1 研究区概况}

艾比湖 $\left(44^{\circ} 54^{\prime} \sim 45^{\circ} 09^{\prime} \mathrm{N}, 82^{\circ} 35^{\prime} \sim 83^{\circ} 10^{\prime} \mathrm{E}\right)$ 是新疆第一大咸水湖, 属构造带上的断陷湖泊, 它与哈 萨克斯坦境内的萨克斯湖、阿拉湖处于同一断陷带上, 是新疆准噶尔盆地西南缘的最低汇水中心, 目前仅 受博尔塔拉河、精河和部分地下水补给, 面积变化于 $500 \sim 600 \mathrm{~km}^{2}$ 之间, 湖面海拔 $189 \mathrm{~m}$, 南西北三面环 山, 东部与准噶尔盆地相连. 受西风环流以及蒙古高压和西伯利亚冷空气的影响, 艾比湖地区表现为典型 的中温带干旱大陆气候, 以干旱少雨、气温变化剧烈为特征 ${ }^{[13]}$, 年均气温 $8.3^{\circ} \mathrm{C}$, 年均降水量 $90.9 \mathrm{~mm}$, 降 水稀少, 蒸发强烈, 常年多风, 每年风速大于 $8 \mathrm{~m} / \mathrm{s}$ 的天数多达 $165 \mathrm{~d}$, 最高瞬时风速可达 $55 \mathrm{~m} / \mathrm{s}$, 多集中在 4-6 月份 ${ }^{[14]}$.

\section{2 样品采集与处理}

在艾比湖东南部历史时期干涸湖底选择一块 (长约 $1500 \mathrm{~m}$, 宽约 $1000 \mathrm{~m}$ ) 植被类型较丰富的采样带 (图 1). 选 择自然状态下典型的 6 种景观类型, 设置 54 个采样点采集沉积物样品, 采样深度为 $0 \sim 30 \mathrm{~cm}$ 和 $30 \sim 60 \mathrm{~cm}$. 每种景观类型下采集 $8 \sim 11$ 个样品. 每个采样点选择相邻 3 个不同的点进行重复取样, 混合组成该样点的待 
测样品, 共采集 216 个样品. 所有采样点均用 GPS 进行定位, 记录样点周围的富盐沉积物特征、植被生长状 况等(表 1).在 2011 年 6 月初(春季)和 2011 年 10 月初(秋季)进行 2 次采样.

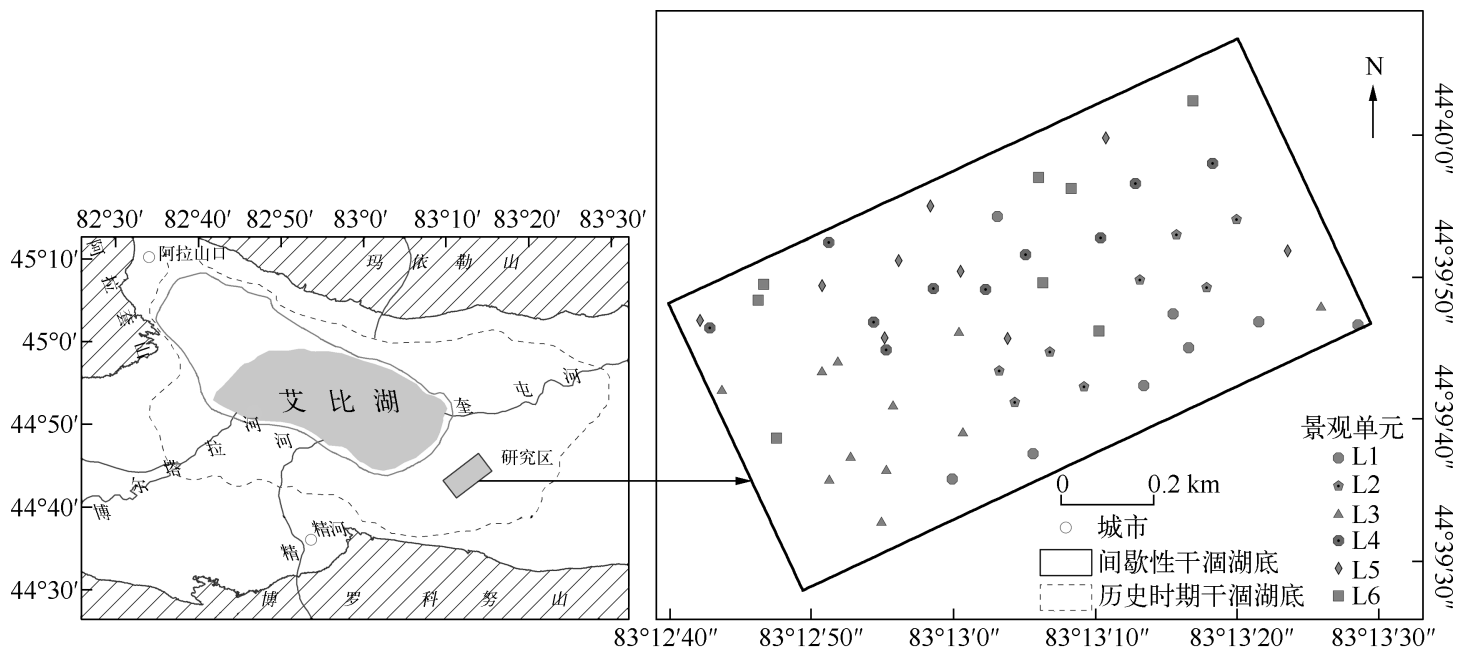

图 1 研究区位置和采样点分布

Fig. 1 Location of study area and distribution of sampling sites

表 1 景观单元及采样数

Tab. 1 Landscape units and number of samples

\begin{tabular}{|c|c|c|c|c|c|}
\hline 标号 & 景观单元 & 主要植物类型 & 采样数 & 采样地描述 & 盖度 \\
\hline L1 & 胡杨林带 & 胡杨 (Populous euphratica) & 8 & 表面粗䊁、较硬、片状盐斑 & $<10 \%$ \\
\hline $\mathrm{L} 2$ & 乔本结合带 & $\begin{array}{l}\text { 罗布麻 (Apocynum venetum }) 、 \text { 胡杨、柽柳 } \\
(\text { Tamarix }) 、 \text { 琵琶柴 }(\text { Reaumuria soongorica })\end{array}$ & 8 & 表面粗糙, 形成一层结晶盐 & $<10 \%$ \\
\hline $\mathrm{L} 3$ & 草本结合带 & $\begin{array}{l}\text { 罗布麻、白刺 ( Nitraria schoberi)、盐爪爪 ( Ka- } \\
\text { lidium foliatum)、琵琶柴 }\end{array}$ & 11 & 表面平整、紧实 & $<10 \%$ \\
\hline L4 & 芦苇荒漠带 & 芦苇( Phragmites australis) & 10 & 表面平整、较硬、紧实 & $<10 \%$ \\
\hline L5 & 梭梭荒漠带 & $\begin{array}{l}\text { 梭梭( Haloxylon ammodendron)、 } \\
\text { 盐节木( Halocnemum strobilaceum) }\end{array}$ & 9 & $\begin{array}{l}\text { 表层平整、质轻, 呈蓬松装的 } \\
\text { 灰白色小颗粒物,颗粒小 }\end{array}$ & $<10 \%$ \\
\hline L6 & 无植被覆盖 & 无 & 8 & $\begin{array}{l}\text { 表面质硬,呈不规则多边形碎 } \\
\text { 块的结晶盐壳 }\end{array}$ & 0 \\
\hline
\end{tabular}

水溶性盐的测定: 将样品自然风干, 研磨并过 $1 \mathrm{~mm}$ 孔径篮. 按照土壤农化分析方法, 土水比按 $1: 5$ 进行浸提液提取 ${ }^{[15]}$. 浸提液在实验室进行水溶性盐分析, 分析项目包括 $\mathrm{Na}^{+} 、 \mathrm{~K}^{+} 、 \mathrm{Ca}^{2+} 、 \mathrm{Mg}^{2+} 、 \mathrm{CO}_{3}^{2-}$ 、 $\mathrm{HCO}_{3}^{-} 、 \mathrm{Cl}^{-} 、 \mathrm{SO}_{4}^{2-}$ 等主要离子含量以及总盐含量. $\mathrm{Cl}^{-}$的测定采用 $\mathrm{AgNO}_{3}$ 滴定法; $\mathrm{Na}^{+} 、 \mathrm{~K}^{+}$的测定采用 火焰光度法 (火焰光度计为 6410 ) ; $\mathrm{Ca}^{2+} 、 \mathrm{Mg}^{2+}$ 的测定采用 EDTA 络合滴定法; $\mathrm{SO}_{4}^{2-}$ 的测定采用 EDTA 间接滴定法; $\mathrm{CO}_{3}^{2-} 、 \mathrm{HCO}_{3}^{-}$的测定采用双指示剂中和法; 沉积物内水溶性盐总量的测定采用残渣烘干一 质量法.

\section{3 数据处理与统计分析}

利用单因素方差分析 (One-way ANOVA) 和双因素方差分析 (Two-way ANOVA) 对不同景观单元盐分数 据进行显著性检验, 使用 Duncan 多重检验方法进行多重比较, $P<0.05$ 为差异显著. 统计分析通过 SPSS 16.0 软件实现, 图形由 Origin 8.5 绘制. 


\section{2 结果与分析}

\section{1 干涸湖底不同景观单元蒸发盐组成特征}

对沉积物中 $\mathrm{Na}^{+} 、 \mathrm{~K}^{+} 、 \mathrm{Ca}^{2+} 、 \mathrm{Mg}^{2+} 、 \mathrm{CO}_{3}^{2-} 、 \mathrm{HCO}_{3}^{-} 、 \mathrm{Cl}^{-} 、 \mathrm{SO}_{4}^{2-}$ 主要离子含量差异和主要盐分类型进行分 析, 明确不同景观单元蒸发盐组成与类型分异特征.

单因素方差分析结果显示: 6 月初不同景观单元 $0 \sim 30 \mathrm{~cm}$ 和 $30 \sim 60 \mathrm{~cm}$ 深度处 $\mathrm{Na}^{+} 、 \mathrm{~K}^{+} 、 \mathrm{Mg}^{2+}$ 的含量均 存在显著差异 $(P<0.05), 10$ 月初也是如此, 2 次采样 $\mathrm{Na}^{+}$含量存在极显著差异 $(P<0.001) .6$ 月初, 不同景 观单元 $0 \sim 30 \mathrm{~cm}$ 和 $30 \sim 60 \mathrm{~cm}$ 深度处 $\mathrm{Ca}^{2+}$ 含量存在显著差异 $(P<0.05) ; 10$ 月初, 不同景观单元 $0 \sim 30 \mathrm{~cm}$ 深度处 $\mathrm{Ca}^{2+}$ 含量差异显著 $(P<0.05), 30 \sim 60 \mathrm{~cm}$ 深度处 $\mathrm{Ca}^{2+}$ 含量无显著差异 $(P>0.05)$.

阳离子含量随深度增加均呈降低的趋势, 6 种不同景观单元中 L5 不同深度阳离子的含量均最高 (图 2). 6 种不同景观单元的多重比较中, 6 月初只有 L5 在 $0 \sim 30 \mathrm{~cm}$ 和 30 60 cm 深度处的 $\mathrm{Na}^{+}$含量与其它 5 种景观 单元存在显著差异 $(P<0.05)$, 随深度增加 $\mathrm{Na}^{+}$含量均降低, 差异显著性降低 $(P<0.05), 10$ 月初不同景观 单元的多重比较相对复杂 (图 2A). 不同景观单元的多重比较显示, $\mathrm{K}^{+}$含量分析结果与 $\mathrm{Na}^{+}$相同 (图 2B). 6 月初和 10 月初不同景观单元不同深度 $\mathrm{Ca}^{2+}$ 含量差别不大 (图 $2 \mathrm{C}$ ), 随深度增加含量均降低, 但 $\mathrm{Ca}^{2+}$ 含量季 节变化不大. 不同景观单元 6 月初和 10 月初 $\mathrm{Mg}^{2+}$ 含量差别较大 (图 2D), 6 月初在 $0 \sim 30 \mathrm{~cm}$ 和 $30 \sim 60 \mathrm{~cm}$ 深度处 L5 与其它景观类型存在显著差异 $(P<0.05), 10$ 月初 L5 与 L6 无显著差异 $(P>0.05)$, 但与其它 4 种景观单元差异显著 $(P<0.05)$; 随深度增加 $\mathrm{Mg}^{2}+$ 含量均降低, 差异显著性降低.

एवि $0 \sim 30 \mathrm{~cm} \quad 60 \mathrm{~cm}$
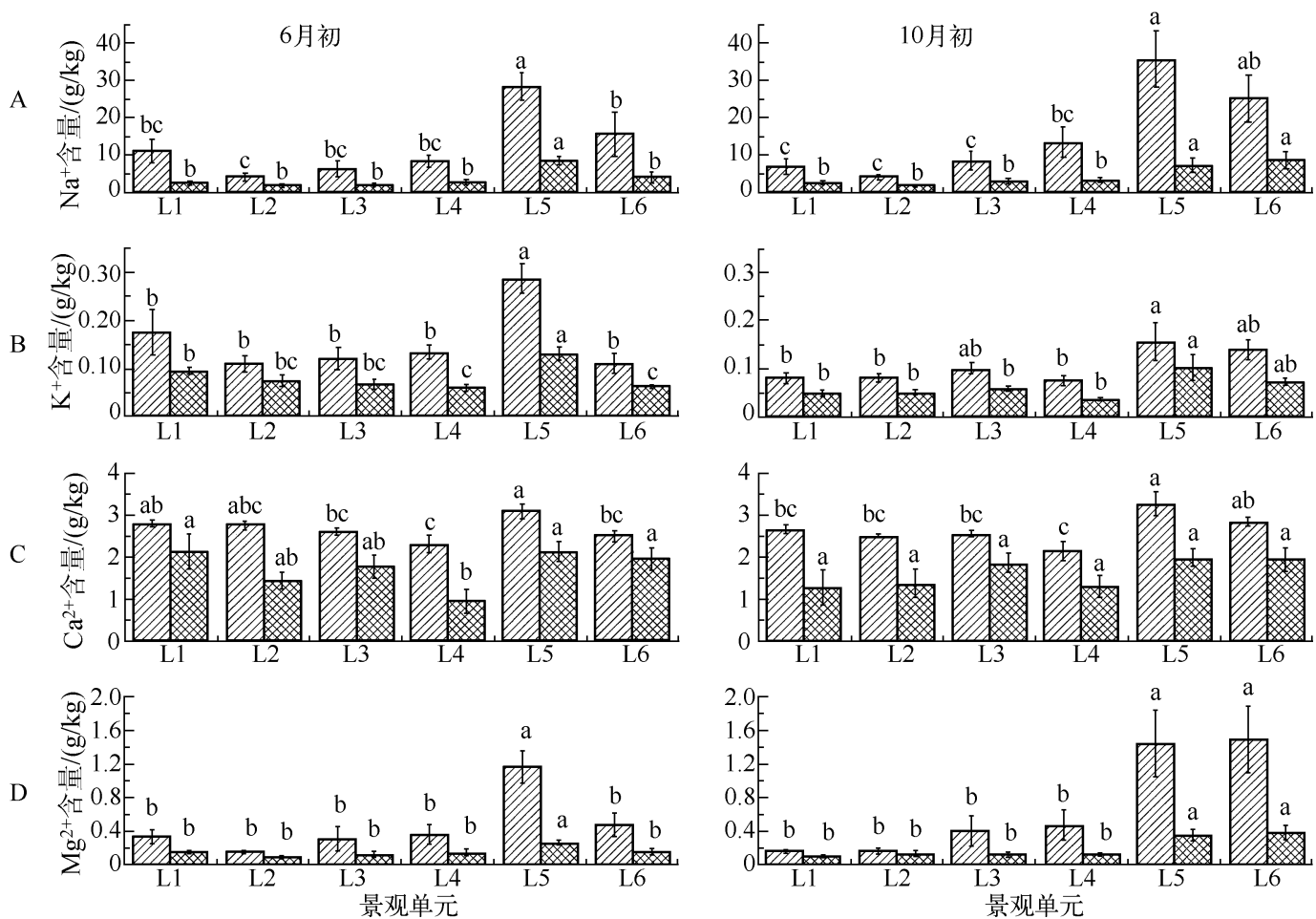

图 2 不同景观单元 6 月初和 10 月初阳离子分布特征 (相同深度间标有不同小写字母表明两者差异显著 $(P<0.05)$,下同)

Fig. 2 Cation distribution characteristics in early June and early October under different landscape units ( different alphabets indicate significant difference between the same $\operatorname{depth}(P<0.05)$, the same below) 
6 月初和 10 月初, 不同景观单元 $0 \sim 30 \mathrm{~cm}$ 和 $30 \sim 60 \mathrm{~cm}$ 深度处 $\mathrm{Cl}^{-} 、 \mathrm{SO}_{4}^{2-}$ 含量存在显著差异 $(P<0.05)$, 其中不同时间不同深度 $\mathrm{Cl}^{-}$含量均存在极显著差异 $(P<0.001) ; 6$ 月初和 10 月初, 不同景观单元 $0 \sim 30 \mathrm{~cm}$ 深度处 $\mathrm{CO}_{3}^{2-}$ 含量存在显著差异 $(P<0.05)$, 然而 $30 \sim 60 \mathrm{~cm}$ 深度处含量差异不显著 $(P>0.05) ; 6$ 月初不同景观单元 $0 \sim 30 \mathrm{~cm}$ 和 $30 \sim 60 \mathrm{~cm}$ 深度处 $\mathrm{HCO}_{3}^{-}$含量差异不显著 $(P>0.05), 10$ 月初不同景观单元 $0 \sim 30 \mathrm{~cm}$ 深度处 $\mathrm{HCO}_{3}^{-}$含量差异显著 $(P<0.05), 30 \sim 60 \mathrm{~cm}$ 深度处 $\mathrm{HCO}_{3}^{-}$含量差异不显著 $(P>0.05)$, 差 异性表现较为复杂.

阴离子含量也随深度增加呈降低的趋势, 6 不同景观单元不同深度阴离子含量也是 L5 最高 (图 3). 6 月 初 $\mathrm{L} 5$ 景观单元不同深度 $\mathrm{Cl}^{-}$含量与其它 5 种景观单元均存在极显著差异 $(P<0.001$, 图 3A). 而其它 5 种景 观单元之间含量差别不大. 不同景观单元中 $\mathrm{L} 5$ 的 $\mathrm{SO}_{4}^{2-}$ 含量仍然最高, 但差异显著性降低 (图 3B); 多重比较 中, 只有 10 月初 $0 \sim 30 \mathrm{~cm}$ 深度处 $\mathrm{SO}_{4}^{2-}$ 含量与其它景观单元存在显著差异 $(P<0.05)$. 不同景观类型下 $\mathrm{CO}_{3}^{2-}$ 含量甚微, 多重比较中, 只有 10 月初 $0 \sim 30 \mathrm{~cm}$ 深度处 $\mathrm{CO}_{3}^{2-}$ 含量存在显著差异 $(P<0.05$, 图 3C $)$. $\mathrm{HCO}_{3}^{-}$含量较 $\mathrm{CO}_{3}^{2-}$ 稍高, 差异显著性与 $\mathrm{CO}_{3}^{2-}$ 相同 (图 3D).

ए7य $0 \sim 30 \mathrm{~cm} \quad 60 \mathrm{~cm}$
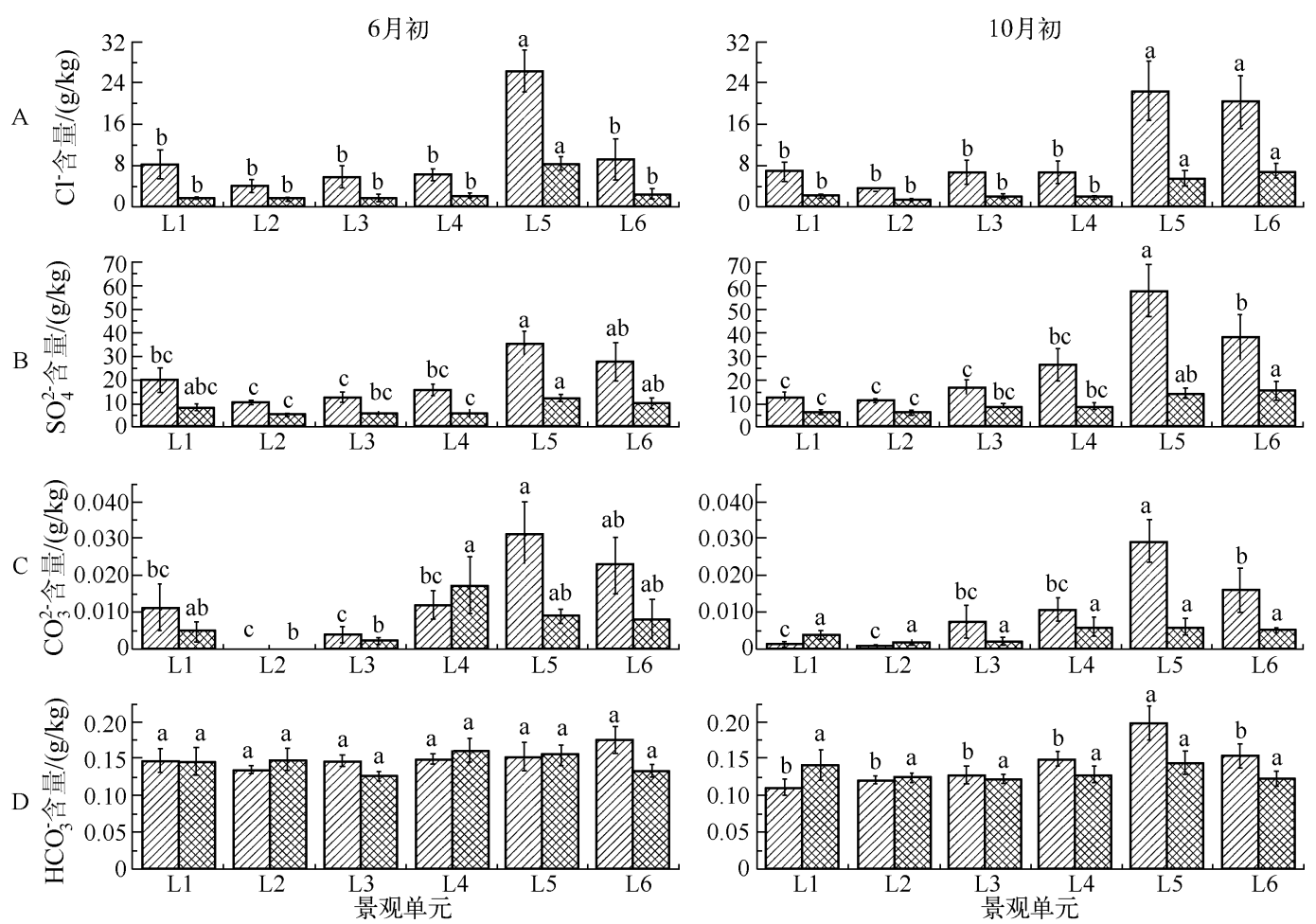

图 3 不同景观单元 6 月初和 10 月初阴离子含量分布特征

Fig. 3 Anion distribution characteristics in early June and early October under different landscape units

不同景观单元的阳离子组成中, $\mathrm{Na}^{+}$和 $\mathrm{Ca}^{2+}$ 含量较高, 其中 $\mathrm{Na}^{+}$含量最高可达 $63.12 \mathrm{~g} / \mathrm{kg}$, 其次是 $\mathrm{Mg}^{2+}, \mathrm{K}^{+}$含量最低(图 2). 阴离子组成中 $\mathrm{Cl}^{-} 、 \mathrm{SO}_{4}^{2-}$ 含量较高, 前者含量最高可达 $45.26 \mathrm{~g} / \mathrm{kg}, \mathrm{HCO}_{3}^{-} 、 \mathrm{CO}_{3}^{2-}$ 含量甚微 (图 3). 可见,艾比湖干涸湖底富盐沉积物的主要盐分类型是 $\mathrm{NaCl}$, 其次是 $\mathrm{CaSO}_{4}$, 其它盐分含量较

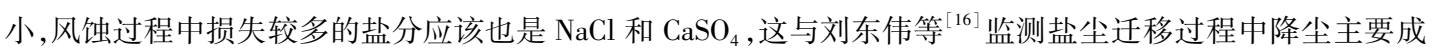
分是氯化物、硫酸盐的结果吻合.

盐分组成成分的分布特征反映了干涸湖底不同景观单元之间盐分的变化趋势. 在明确干涸湖底组成特 征的前提下, 揭示不同景观单元下盐分含量的分布与变化特征, 可以更好地理解干涸湖底风蚀和盐尘暴形 
成过程中盐分释放的分异特征.

\section{2 干涸湖底不同景观单元蒸发盐的分布与变化特征}

干涸湖底不同景观单元不同深度沉积物盐分含量存在显著差异 $(P<0.05$, 图 4$)$, 说明不同景观类型对 盐分含量有显著影响. 6 月初和 10 月初, 不同景观单元 $0 \sim 30 \mathrm{~cm}$ 深度处沉积物盐分含量的分布规律不同:6 月初盐分含量的大小顺序是 $\mathrm{L} 5(98.09 \mathrm{~g} / \mathrm{kg})>\mathrm{L} 6(59.38 \mathrm{~g} / \mathrm{kg})>\mathrm{L} 1(44.04 \mathrm{~g} / \mathrm{kg})>\mathrm{L} 4(34.64 \mathrm{~g} / \mathrm{kg})>\mathrm{L} 3$ $(29.13 \mathrm{~g} / \mathrm{kg})>\mathrm{L} 2(22.25 \mathrm{~g} / \mathrm{kg}), 10$ 月初盐分含量大小顺序是 $\mathrm{L} 5(127.53 \mathrm{~g} / \mathrm{kg})>\mathrm{L} 6(95.10 \mathrm{~g} / \mathrm{kg})>\mathrm{L} 4$ $(51.65 \mathrm{~g} / \mathrm{kg})>\mathrm{L} 3(36.23 \mathrm{~g} / \mathrm{kg})>\mathrm{L} 1(30.37 \mathrm{~g} / \mathrm{kg})>\mathrm{L} 2(22.02 \mathrm{~g} / \mathrm{kg})$. L5 的盐分含量最高, 忽略蒸发强度的 差异, 这在一定程度上说明梭梭荒漠带具有较强的抗风蚀效应. 盐分含量的最低值出现在 L2, 而不是无植被 覆盖的 L6, 说明 L2 风蚀较严重,无植被覆盖的 L6 更有利于盐分的积累.

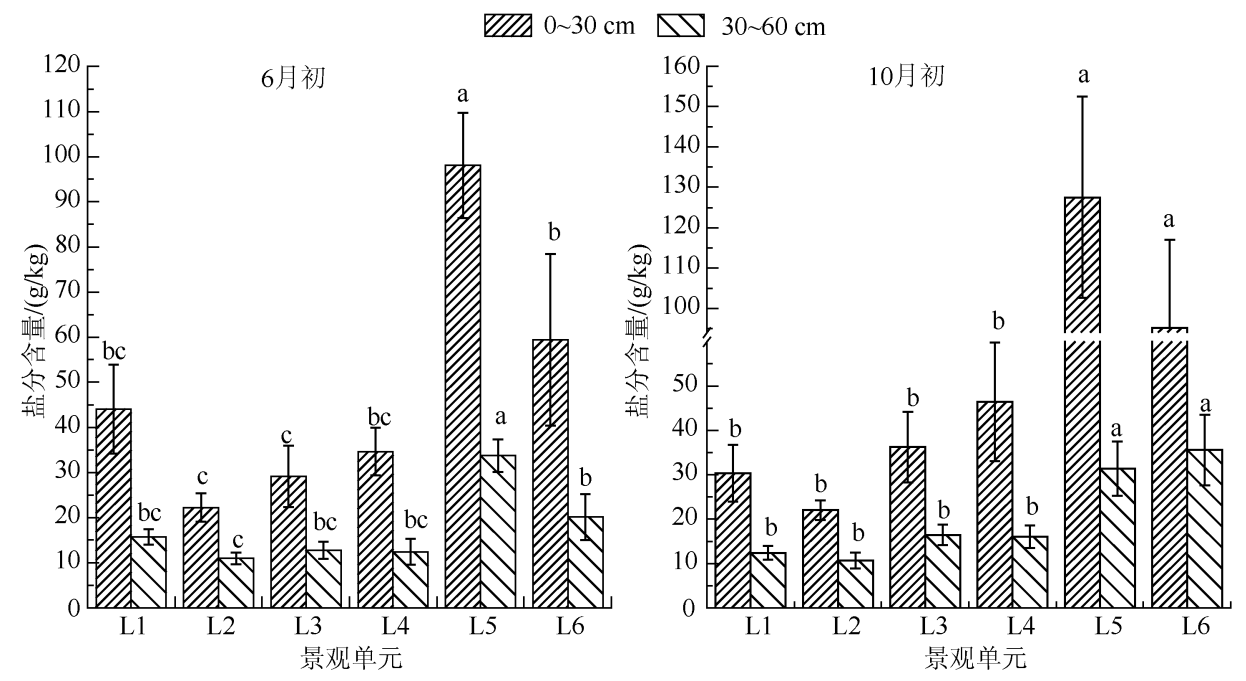

图 4 不同景观单元 6 月初和 10 月初盐分含量分布特征

Fig. 4 Salinity content distribution characteristics in early June and early October under different landscape units

不同景观单元 30 60 cm 深度处沉积物的盐分含量顺序为:6月初为 $\mathrm{L} 5(33.71 \mathrm{~g} / \mathrm{kg})>\mathrm{L} 6(20.15 \mathrm{~g} / \mathrm{kg})>\mathrm{L} 1$ $(15.67 \mathrm{~g} / \mathrm{kg})>\mathrm{L} 3(12.74 \mathrm{~g} / \mathrm{kg})>\mathrm{L} 4(12.41 \mathrm{~g} / \mathrm{kg})>\mathrm{L} 2(10.93 \mathrm{~g} / \mathrm{kg}) ; 10$ 月初为 $\mathrm{L} 6(35.60 \mathrm{~g} / \mathrm{kg})>\mathrm{L} 5$ $(31.40 \mathrm{~g} / \mathrm{kg})>\mathrm{L} 3(16.50 \mathrm{~g} / \mathrm{kg})>\mathrm{L} 4(16.00 \mathrm{~g} / \mathrm{kg})>\mathrm{L} 1(12.40 \mathrm{~g} / \mathrm{kg})>\mathrm{L} 2(10.70 \mathrm{~g} / \mathrm{kg})$. 但各 $30 \sim 60 \mathrm{~cm}$ 深 度处景观单元之间盐分含量差别较 $0 \sim 30 \mathrm{~cm}$ 小.

随着深度的增加, 不同景观单元沉积物中的盐分含量均呈现降低的趋势, 表明干涸湖底有强烈的盐分 表聚现象,这种表聚现象的统计表明不同景观单元 $0 \sim 30 \mathrm{~cm}$ 和 $30 \sim 60 \mathrm{~cm}$ 深度处的盐分含量均存在显著差 异 $(P<0.05)$, 其中, L5 不同深度之间盐分含量存在极显著差异 $(P<0.01)$, 其它景观单元下均存在显著差 异 $(P<0.05)$ (图 4$)$.

随着时间的变化, 不同景观单元盐分表聚程度的变化不同: L2、L3、L4、L5、L6 有不同程度的增强, 只有 L1 表聚程度减弱,即随着时间变化,L2、L3、L4、L5、L6 表层盐分含量增加, 而 L1 减少. 原因是 5 月以后,由于大 量的农业用水和水面高温蒸发, 艾比湖水面逐渐萎缩 ${ }^{[17]}$,地下水位下降,风蚀在 6 月达到最强. 6-10月,风蚀 强度相对减弱,但蒸发相对增强,在毛管效应作用下,盐分随水分的表聚增强,但因风蚀损失减少,盐分表现出 增加的趋势. L1 盐分含量表现为减少,可能是因为该景观单元较低的植被覆盖度,对风速的减弱作用没有其它 景观单元明显,表层疏松的片状盐斑(表 1) 沉积物极易发生蠕移、跃移碰撞释放盐尘,导致盐分含量减少.

6 种景观单元不同深度盐分含量的双因素方差分析见表 2. 不同景观单元、不同深度以及景观和深度的 交互作用对盐分含量存在极显著影响 $(P<0.01)$, 表明不同的景观类型对盐分含量有显著影响, 且盐分含量 在垂直方向上有显著差异的表聚现象. 
表 2 不同景观单元不同深度下盐分含量的双因素方差分析

Tab. 2 Two-way ANOVA of salt content of different depths under different landscape units

\begin{tabular}{|c|c|c|c|c|c|c|}
\hline 取样时间 & 变异来源 & 自由度 & 平方和 & 均方和 & $F$ & sig. \\
\hline \multirow[t]{5}{*}{6 月初 } & 深度 & 1 & 24439.868 & 24439.868 & 49.661 & $<0.001$ \\
\hline & 景观 & 5 & 29640.530 & 5928.106 & 12.046 & $<0.001$ \\
\hline & 深度 ×景观 & 5 & 8385.470 & 1677.094 & 3.408 & 0.007 \\
\hline & 误差 & 96 & 47244.576 & 492.131 & & \\
\hline & 总变异 & 108 & 109710.444 & & & \\
\hline \multirow[t]{5}{*}{10 月初 } & 深度 & 1 & 41960.993 & 41960.993 & 38.456 & $<0.001$ \\
\hline & 景观 & 5 & 57570.820 & 11514.164 & 10.553 & $<0.001$ \\
\hline & 深度 $\times$ 景观 & 5 & 23268.150 & 4653.630 & 4.265 & 0.002 \\
\hline & 误差 & 96 & 104748.480 & 1091.130 & & \\
\hline & 总变异 & 108 & 227548.443 & & & \\
\hline
\end{tabular}

\section{3 讨论}

干旱区独特的山地、绿洲及荒漠系统 (MODS) 塑造了不同特性的尾问湖泊. 作为区域水循环的重要组成 部分, 艾比湖不断收纳着通过地表水和地下水进入湖泊的盐分和养分, 成为特有的“收容站”. 随着湖泊的快 速大面积干涸, 盐分含量较高的沉积物裸露于空气, 在强烈的蒸发作用下, 大量的盐分随着水分蒸发不断向 表面运动,进而增加了表面盐分含量. 与此同时, 艾比湖干涸湖底强烈的风蚀作用可以带走大量的盐分. 由 于干涸湖底不同的植被覆盖状况，导致盐分损失不同，造成干涸湖底不同景观单元盐分分布的空间差异.

艾比湖干涸湖底的蒸发盐主要是在蒸发作用下地下水中溶解质表聚形成的 ${ }^{[18]}$. 因此, 蒸发强度、地下水 矿化度、地下水埋深及沉积物性质等因素决定了溶解质在干涸湖底的表聚程度. 但本文选择小尺度范围内 6 种不同的景观类型, 其气候条件相对均一, 地下水矿化度、地下水埋深及沉积物性质差别不大, 不同的景观 类型以及受其影响的蒸发强度成为影响盐分分布的重要因素.

选择自然状态下胡杨林带 (L1)、乔本结合带 ( L2)、草本结合带 ( L3)、芦苇荒漠带 ( L4) 、梭梭荒漠带 (L5)、无植被覆盖 (L6)6 种景观单元作为研究对象, 分析了其沉积物中盐分组成和总盐含量的分布和变化 特征. 总体来看, 不同景观单元沉积物中 $\mathrm{Na}^{+} 、 \mathrm{~K}^{+} 、 \mathrm{Ca}^{2+} 、 \mathrm{Mg}^{2+} 、 \mathrm{CO}_{3}^{2-} 、 \mathrm{HCO}_{3}^{-} 、 \mathrm{Cl}^{-}$和 $\mathrm{SO}_{4}^{2-}$ 含量和总盐含量差 异明显. 不同景观单元阳离子组成中, $\mathrm{Na}^{+}$和 $\mathrm{Ca}^{2+}$ 含量较高, $0 \sim 30 \mathrm{~cm}$ 和 $30 \sim 60 \mathrm{~cm}$ 深度处 $\mathrm{Na}^{+} 、 \mathrm{~K}^{+}$含量均 存在显著差异 $(P<0.05)$, 不同景观单元阴离子组成中 $\mathrm{Cl}^{-} 、 \mathrm{SO}_{4}^{2-}$ 含量较高, $0 \sim 30 \mathrm{~cm}$ 和 $30 \sim 60 \mathrm{~cm}$ 深度处 $\mathrm{Cl}^{-} 、 \mathrm{SO}_{4}^{2-}$ 含量存在显著差异 $(P<0.05)$. 可以看出, 艾比湖干涸湖底沉积物的主要盐分类型是 $\mathrm{NaCl}$ 和 $\mathrm{CaSO}_{4}$, Reheis 等研究指出干涸湖底表面形成的盐分主要是 $\mathrm{NaCl}_{1} \mathrm{CaSO}_{4} \cdot 2 \mathrm{H}_{2} \mathrm{O}$ 等蒸发盐矿物 ${ }^{[19]}$, 但本研究 这些盐分究竟是石膏类型的带结晶水硫酸钙, 还是硬石膏类型的无水硫酸钙尚不明确, 在后续研究中会从 结晶矿物学的角度进行分析.

无论是盐分组成成分还是总盐含量, L5 均最高, 其次是 L6, 而 L2 均最低, 其它 3 种景观单元之间相差 不大. 这可能是因为在实际环境中, L2 因其本身高大但稀疏的形态特征, 加之植被覆盖度较低导致盐分随强 烈的蒸发表聚后形成疏松的表层沉积物, 成为易发生侵蚀的部位, 表现为侵蚀较严重, 盐分损失严重; 而无 植被覆盖的 L6 在强烈蒸发作用下, 大量的盐分表聚, 盐分与沉积物颗粒形成微团粒结构, 当环境过于干燥 时盐分凝聚板结, 形成了坚硬的硬质盐壳 (表 1). 盐壳本身是一种盐结皮, 表面坚硬, 结构紧密, 其表层尘粒 临界启动风速大, 较难风蚀, 但在冻融交替时节有一定程度的风蚀. 梭梭荒漠带 L5 由于植被本身冠幅较大, 可以有效减小风速, 在覆盖度和蒸发强度差别不大的情况下, 可以有效减少风对该种景观单元地表的吹蚀, 侵蚀量自然会小一些. 研究结果与很多学者在干涸湖底人工种植梭梭 ${ }^{[7,12,20]}$, 通过生物工程防止湖底风蚀的 建议是一致的.

\section{4 结论}

选择艾比湖干涸湖底自然状态下典型的 6 种景观单元, 采集不同景观单元下的样品, 通过数理统计分 
析方法对可溶性离子和总盐含量进行分析, 揭示了艾比湖干涸湖底不同景观单元蒸发盐的分布与变化 特征.

1) 在沉积物盐分组成方面, 6 月初不同景观单元 $0 \sim 30 \mathrm{~cm}$ 和 $30 \sim 60 \mathrm{~cm}$ 深度处 $\mathrm{Na}^{+} 、 \mathrm{~K}^{+} 、 \mathrm{Mg}^{2+}$ 的含量 均存在显著差异, 10 月初也是如此. 其中两次采样 $\mathrm{Na}^{+}$含量存在极显著差异. 6 月初和 10 月初, 不同景观单 元 $0 \sim 30 \mathrm{~cm}$ 和 $30 \sim 60 \mathrm{~cm}$ 深度处 $\mathrm{Cl}^{-} 、 \mathrm{SO}_{4}^{2-}$ 含量存在显著差异, 其中不同时间不同深度 $\mathrm{Cl}^{-}$含量均存在极显 著差异;6 月初和 10 月初,不同景观单元 $0 \sim 30 \mathrm{~cm}$ 处深度 $\mathrm{CO}_{3}^{2-}$ 含量存在显著性差异,然而 $30 \sim 60 \mathrm{~cm}$ 深度 处 $\mathrm{CO}_{3}^{2-}$ 含量差异不显著; 6 月初不同景观单元 $0 \sim 30 \mathrm{~cm}$ 和 $30 \sim 60 \mathrm{~cm}$ 深度处 $\mathrm{HCO}_{3}^{-}$含量差异不显著, 10 月 初不同景观单元 $0 \sim 30 \mathrm{~cm}$ 深度处 $\mathrm{HCO}_{3}^{-}$含量差异显著, $30 \sim 60 \mathrm{~cm}$ 深度处 $\mathrm{HCO}_{3}^{-}$含量差异不显著, 差异性表 现较为复杂. 艾比湖干涸湖底的富盐沉积物的主要盐分类型是 $\mathrm{NaCl}$, 其次是 $\mathrm{CaSO}_{4}$, 其它盐分含量较小.

2) 在沉积物总盐含量方面,干涸湖底不同景观单元、不同深度富盐沉积物盐分含量存在显著差异,说明 不同的景观类型对盐分含量有显著影响. 随着深度的增加, 不同景观单元沉积物中的盐分含量均呈现降低 的趋势, 表明干涸湖底有强烈的盐分表聚现象. 随着时间变化, 不同景观类型表聚程度变化不同: L2、L3、L4、 L5、L6 有不同程度的增强,只有 L1 表聚程度减弱.

3) 无论是盐分组成成分还是总盐含量, 景观单元 L 5 的含量均最高, 其次是 L6, 而 L2 的含量均最低, 其 它 3 种景观单元之间差异不显著. 在无植被覆盖和植被覆盖稀疏的干涸湖底, 蒸发强度、地下水矿化度、地 下水埋深及沉积物质地等因素决定了盐分在干涸湖底的表聚程度. 研究结果显示, 在小尺度范围内,局地气 候条件相对均一,地下水矿化度、地下水埋深及沉积物性质差别不大,不同景观类型是影响盐分表聚以及分 布与变化的主要因素.

\section{5 参考文献}

[ 1 ] Barth HJ. Comment on: Playa, playa lake, sabkha: Proposed definitions for old terms. Journal of Arid Environments, $2001,47(4): 513-514$.

[ 2 ] Briere PR. Playa, playa lake,sabkha: Proposed definitions for old terms. Journal of Arid Environments, 2000, 45(1): 1-7.

[ 3 ] Gill TE. Eolian sediments generated by anthropogenic disturbance of playas: Human impacts on the geomorphic system and geomorphic impacts on the human system. Geomorphology, 1996, 17 (1/2/3) : 207-228.

[ 4 ] Goudie AS, Wells GL. The nature, distribution and formation of pans in arid zones. Earth-Science Reviews, 1995,38 (1) : $1-69$

[ 5 ] 柏春广,穆桂金. 艾比湖的湖岸地貌及其反映的湖面变化. 干旱区地理, 1999,22(1) :34-40.

[6]秦伯强. 近百年来亚洲中部内陆湖泊演变及其原因分析. 湖泊科学,1999,11(1):11-19.

[ 7 ] 苏颖君,包安明. 艾比湖生态环境恶化及防治对策. 干早区地理,2002,25(2):143-148.

[ 8 ] Mees F, Singer A. Surface crusts on soils/sediments of the southern Aral Sea basin, Uzbekistan. Geoderma, 2006,136 (1) : $152-159$

[ 9 ] Singer A, Zobeck T, Poberezsky L et al. The $\mathrm{PM}_{10}$ and $\mathrm{PM}_{2.5}$ dust generation potential of soils/sediments in the Southern Aral Sea Basin, Uzbekistan. Journal of Arid Environments, 2003, 54(4) : 705-728.

[10］杨 青,何 清,李红军等. 艾比湖流域沙尘气候变化趋势及其突变研究. 中国沙漠,2003,23(5):503-508.

[11] Abuduwaili J, Liu DW, Wu GY. Saline dust storms and their ecological impacts in arid regions. Journal of Arid Land, 2010, $2(2)$ : 144-150.

[12] 吉力力 ·阿不都外力,徐俊荣,穆桂金等. 艾比湖盐尘对周边地区土壤盐分及景观变化的影响. 冰川冻土,2007,29 (6) :928-939.

[13] 王 宏, 谢 霞,㚞亚辉等. 新疆艾比湖地区不同土地利用类型的土壤盐渍化敏感性评价. 地理科学进展,2011,30 (5) :593-599.

[14] 图尔苏诺夫 AA, 买合皮尔 - 加帕尔. 亚洲中部湖泊水生态学概论. 乌鲁木齐: 新疆科技卫生出版社,1996.

[15］鲍士旦.土壤农化分析. 北京:中国农业出版社,1999:178-200.

[16] 刘东伟,吉力力. 阿不都外力,穆桂金等. 艾比湖干涸湖底化学组成及盐尘的风运堆积. 中国环境科学, 2009,29 (2) : 157-162.

[17］钱亦兵,吴兆宁,蒋 进等. 近 50a 来艾比湖流域生态环境演变及其影响因素分析. 冰川冻土,2004,26(1):17-26. 
[18 ] Reynolds RL, Yount JC, Reheis M et al. Dust emission from wet and dry playas in the Mojave desert, USA. Earth Surface Processes and Landforms, 2007, 32(12) : 1811-1827.

[19] Reheis MC, Budahn JR, Lamothe PJ et al. Compositions of modern dust and surface sediments in the Desert Southwest, United States. Journal of Geophysical Research-Earth Surface, 2009, 114: F01028. doi:10. 1029/2008JF001009.

[20］冊兆鹏, 金海龙, 王范霞. 艾比湖退化湿地的生态恢复. 水土保持学报, 2012,26(3):211-221. 